\title{
CANON Y REPERTORIO FANTÁSTICO EN LAS ESCRITORAS DE MICRORRELATO
}

\author{
XAQUín NúÑEZ SABARÍS \\ Universidade do Minho \\ xnunez@ilch.uminho.pt
}

Enviado: 28-06-2021

Aceptado: 08-12-2021

RESUMEN

La narrativa breve, y muy especialmente el microrrelato, ha sido un género propicio para el tratamiento de lo fantástico. La quiebra de la frontera entre lo real y lo imaginado, soñado, insólito o inverosímil encajaba en las estrategias de elipsis e intensidad del relato corto.

En este artículo nos proponemos abordar, dentro de este paradigma, un doble objetivo. Por un lado, analizar la posición canónica de las escritoras de narrativa breve, utilizando el corpus de seis antologías de microrrelato, que integra la base de datos relacional (http://cehum.ilch.uminho.pt/microrrelatos_xaquinnunez). En segundo lugar, tomando también como punto de partida los textos que integran dicho corpus, clasificar los microrrelatos escritos por mujeres, a fin de analizar los elementos fantásticos que predominan, desde el punto de vista temático, narrativo o intertextual.

Palabras ClAVE fantástico; microrrelato; escritoras; antologías

THE CANON AND THE REPERTOIRE OF THE FANTASTIC IN WOMEN WRITERS OF MICRO-STORIES

\section{ABSTRACT}

The short story, and especially the micro-story, has been a favourable genre for the treatment of the fantastic. The breaking of the boundary between the real and the imagined, dreamed, unusual or implausible fits in with the strategies of ellipsis and the intensity of the short story. 
In this article we propose to address, within this paradigm, a twofold objective. On the one hand, to analyse the canonical position of women short story writers, using the corpus of six micro-story anthologies, which are included in the relational database (http:/ / cehum.ilch.uminho.pt/microrrelatos_xaquinnunez). Secondly, also taking as a starting point the texts that make up this corpus, to classify the micro-stories written by women, in order to analyse the fantastic elements that predominate, from a thematic, narrative or intertextual point of view.

KEYWORDS: fantastic; micro-story; women writers; anthologies

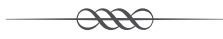

\section{Microrrelato, FANTÁStico y CAMPO LITERARio}

Fantástico y microrrelato han compuesto un binomio que se ha conjugado con cierta frecuencia en la literatura actual. La combinación de ambos suponía una impugnación de las convenciones diegéticas más tradicionales, casando muy bien con la estética que se fue abriendo paso en la posmodernidad y que se acomoda a las preferencias de los lectores de nuestros días. Ya sea en literatura, cine o televisión la quiebra del principio de autoridad, la fragmentación y fractalidad narrativa, los juegos de tiempo y memoria, las grietas entre la delgada línea que separa lo real de lo sobrenatural se han impuesto en una canonicidad narrativa que desafía constantemente la lectura realista.

Este trabajo pretende centrarse en la expresión fantástica de los microrrelatos, teniendo en cuenta el peso que la primera tiene en el repertorio de los segundos. Roas y Casas (2016), por ejemplo, estudiaron la articulación entre fantástico e hiperbrevedad y la irrupción de ambos elementos en el sistema literario contemporáneo. A su vez, Núñez Sabarís y Ribeiro (2020) constatamos, desde una perspectiva cuantitativa, cómo lo fantástico es una de las estrategias narrativas con mayor presencia en el repertorio microcuentístico.

De hecho, el análisis que ahora desarrollaré y los resultados que se pretenden alcanzar se enmarcan en una línea de investigación acerca del comportamiento del microrrelato en el campo literario, que parte de la información reunida en la base de datos en abierto (Núñez Sabarís, 2017). 
En ella, se estudian las antologías de microrrelatos publicadas por editoriales españolas y se ofrece, de forma relacional, información sobre los textos seleccionados (fuentes bibliográficas), autores (nacionalidad, género o fecha de nacimiento) o las publicaciones de procedencia de los microrrelatos.

Dentro de los datos sistémicos que nos ofrece este corpus, nos centraremos en las escritoras, a fin de analizar la posición que ocupan en una forma emergente como el microrrelato y cómo se materializa su escritura. Tomando en consideración los principios editoriales de las diferentes antologías, se tratará de responder a las siguientes cuestiones: ¿cuál es su posición cuantitativa en el conjunto de las antologías? ¿cómo se articula su presencia, en función de los criterios selectivos de cada una de ellas?. ¿existe alguna correlación entre frecuencia y posición sistémica?, o ¿qué papel juega lo fantástico en el repertorio de la literatura hiperbreve y cómo se puede categorizar desde las voces femeninas? Son algunas de las cuestiones que pretendemos resolver a lo largo de este trabajo.

\section{LAS ESCRITORAS EN EL MICRORRELATO}

Las antologías suponen uno de los principales instrumentos de canonización y un factor imprescindible para evaluar el comportamiento del campo literario, o de un determinado valor en dicho campo. En el caso que nos ocupa - el microrrelato - la prolijidad antológica de la primera década del presente siglo nos hace ver la pujanza con la que irrumpió la minificción en este período y la necesidad de categorizar, clasificar y definir una forma literaria que - si no inédita - había sido residual en la canonicidad narrativa anterior al siglo XXI. Nada menos que seis antologías, en editoriales españolas, en poco más de diez años para divulgar a escritores y textos y ofrecer estudios críticos e información relevante para comprender la literatura hiperbreve. Las propuestas editoriales de Obligado (2001 y 2009), Lagmanovich (2005), Encinar y Valcárcel (2011), Andres-Suárez (2012) y Valls (2012) supusieron, por lo tanto, una notable contribución en la difusión y canonización de la micronarrativa en la literatura hispánica. ${ }^{1}$

1 No son las únicas antologías que se publicaron en este período, pero se trata de las que pretendían ofrecer — con distintos propósitos editoriales y selectivos - un panorama sistémico del microrrelato en el mundo hispánico. Los criterios de selección del corpus están especificados en Núñez Sabarís (2017). 
Todas ellas parten de presupuestos diferentes. Lagmanovich (2005) y Andres-Suárez (2012) persiguen una finalidad historiográfica y ofrecen un repaso diacrónico, que se remonta desde inicios del xx hasta la actualidad, si bien que, en el caso de la primera selección, alcanza a toda la geografía hispana, mientras en la segunda queda restringida al ámbito español. Las dos antologías de Obligado (2001 y 2009) tampoco presentan restricciones diacrónicas, reuniendo a escritoras y escritores de diferentes épocas, pero no tiene por objeto la clasificación historiográfica que está en los propósitos editoriales de las dos anteriores. De hecho, si Lagmanovich (2005) y Andres-Suárez (2012) optan por una organización diacrónica creciente, Obligado (2001 y 2009) lo hace en función del tamaño de los textos, siguiendo una lógica decreciente, simulando el afilamiento de la cola del dinosaurio que ilustra las cubiertas.

Por último, Encinar y Valcárcel (2011) y Valls (2012) delimitan los autores y textos al período actual. En la primera antología el arco temporal se sitúa en textos publicados entre 1970 y 2010 y, en la segunda, la restricción es todavía mayor, ya que la referencia en este caso no son los textos, sino el año de nacimiento de los autores: se incluyen microrrelatos de escritores nacidos a partir del 1960. Otra diferencia entre ambas radica también en el alcance geográfico. Encinar y Valcárcel (2011) incluyen a escritores españoles e hispanoamericanos, que hubiesen publicado al menos un libro de microrrelatos, y Valls (2012) se centra exclusivamente en escritoras y escritores españoles.

El notable conjunto de antologías de la primera década contrasta con la escasa producción y publicación de antologías en esta segunda década del milenio. ${ }^{2}$ Las clasificaciones, los compilatorios bibliográficos [Andres-Suárez (2013) y Hernández y Valls (2014)], los debates sobre si se trata o no de un nuevo género narrativo ${ }^{3}$ o los conceptos para acuñarlo han cedido protagonismo a otras cuestiones, centradas en las relaciones intermediales (con otros géneros y medios narrativos, con imagen -fotografía y pintura- o con música), en su recorrido hipermedial o su génesis, comportamiento y mutabilidad en los entornos digitales y el universo tecnológico.

2 Algunas ciertamente interesantes para la arqueología del microrrelato como la de Hernández (2016), que se centra en el modernismo y las vanguardias. A este respecto hay que advertir que incluso muchos de los microrrelatos de los escritores modernistas o de vanguardia fueron rescatados y publicados en libros del siglo xxI, constatando la legitimación del género en el momento actual.

3 En Núñez Sabarís (2013) efectúo una síntesis acerca del debate sobre la cuestión del género literario del microrrelato. 
En todo caso, las antologías ya publicadas nos siguen ofreciendo información de interés para cuantificar y cualificar el comportamiento sistémico del microrrelato, analizar las tendencias actuales y ponderar las estrategias narrativas y temas predominantes en su repertorio. A efectos de evaluar la visibilidad de las autoras y su protagonismo en los procesos de consolidación y legitimación de la minificción se ponen de manifiesto aspectos reveladores del papel de las creadoras. También, como veremos, en un análisis más cualitativo cómo desarrollan lo fantástico en sus microrrelatos.

Su inclusión en las antologías analizadas nos revela datos de interés, tanto si nos centramos en el conjunto de las seis publicaciones, como si reducimos el foco a cada una de ellas, atendiendo a sus propósitos editoriales y a los criterios selectivos utilizados.

En su totalidad arroja un porcentaje global de un tercio de presencia femenina en el cómputo agregado de las seis antologías. De los 300 autores incluidos en ellas, un $29 \%$ son escritoras y un $71 \%$ escritores, con frecuencias variables: hay escritoras incluidas en varias antologías, con diferentes textos en cada una de ellas, y otras que aparecen apenas una sola vez y con un único texto.

Este menor protagonismo femenino no supone una novedad, una vez que resulta correlativo con la proporción de escritoras y escritores que participan en la actividad literaria contemporánea. En el Libro Blanco del Escritor (Sobre la situación profesional de los escritores en España) (Asociación Colegial de Escritores de España, 2019) se detalla que, de los 603 autores que respondieron al cuestionario para dicho informe, un 36’3\% son mujeres, frente al 63,7\% de hombres (Asociación Colegial de Escritores de España, 2019: 51). Un resultado similar arroja una consulta análoga realizada a escritores y escritoras gallegas (Asociación de Escritoras e Escritores en Lingua Galega, 2020), también con la finalidad de elaborar un libro blanco. De los 141 encuestados (que responden a una estimativa del 30\% del total de personas que se dedican a la creación literaria), un $63 \%$ son hombres, un 35\% mujeres y un $2 \%$ se reconocen en otras identidades de género.

De modo que, de los 300 autores que con distinta frecuencia forman parte de estas antologías, la representatividad, en cuanto al género, es similar a la verificada en otros estudios y con otras poblaciones, si bien, como veremos, la oscilación entre las diferentes antologías es notable.

En cuanto a la franja de edad, el grupo mayoritario corresponde a las autoras nacidas entre 1960 y 1979 : 


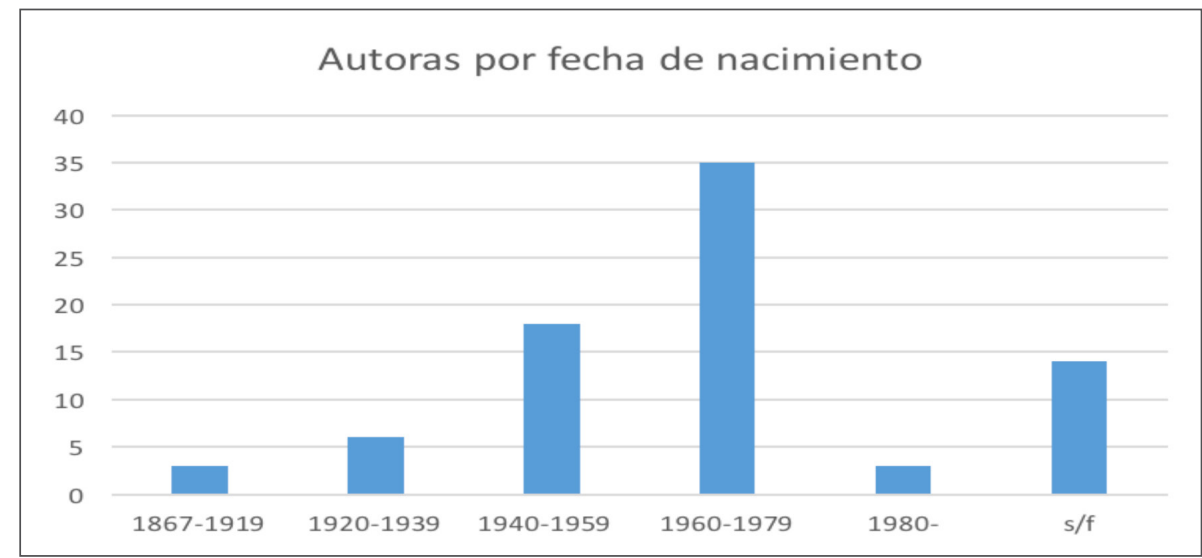

Gráfico 1 (Elaboración propia)

El resultado responde a dos factores relacionados. Por un lado, tal como se ha mencionado, la expansión de la minificción en el presente siglo hace que el microrrelato sea cultivado con mayor frecuencia por escritoras y escritores jóvenes. Por otro, teniendo en cuenta los criterios de las antologías de Encinar y Valcárcel (2011) y sobre todo de Valls (2012), que filtra por año de nacimiento, es lógico el predominio de este arco etario. El notable porcentaje de escritoras sin fecha de nacimiento atribuido obedece a que las publicaciones de Obligado (2001 y 2009) se guían por la calidad y representatividad de los textos, según los criterios editoriales, y no tanto por la canonización y reconocimiento de su obra, lo que dificulta, en ocasiones, el rastreo de sus datos personales. Su participación en actividades culturales diversas o en los talleres de creación literaria de Clara Obligado explica su inclusión en ambas publicaciones.

La base de datos también permite filtrar la mayor o menor presencia de las autoras, y, por consiguiente, su centralidad en la minificción. El siguiente gráfico muestra las más frecuentes por el número de microrrelatos de su autoría incluidos en las diferentes antologías (ver gráfico 2).

Como se puede observar, comparando estos dos primeros gráficos, las escritoras que con mayor frecuencia aparecen no pertenece al grupo más numeroso (las nacidas entre 1960 y 1979). De las diez con mayor presencia, solamente Carmela Greciet se incluiría en él, ya que la mayoría forman parte del segmento de edades comprendidas entre 1940 y 1959. Incluso figura Ana María Matute, que pertenece a la generación de los nacidos en la década del 20, y Luisa Valenzuela, aunque ya muy cerca, por edad, de la siguiente franja. 

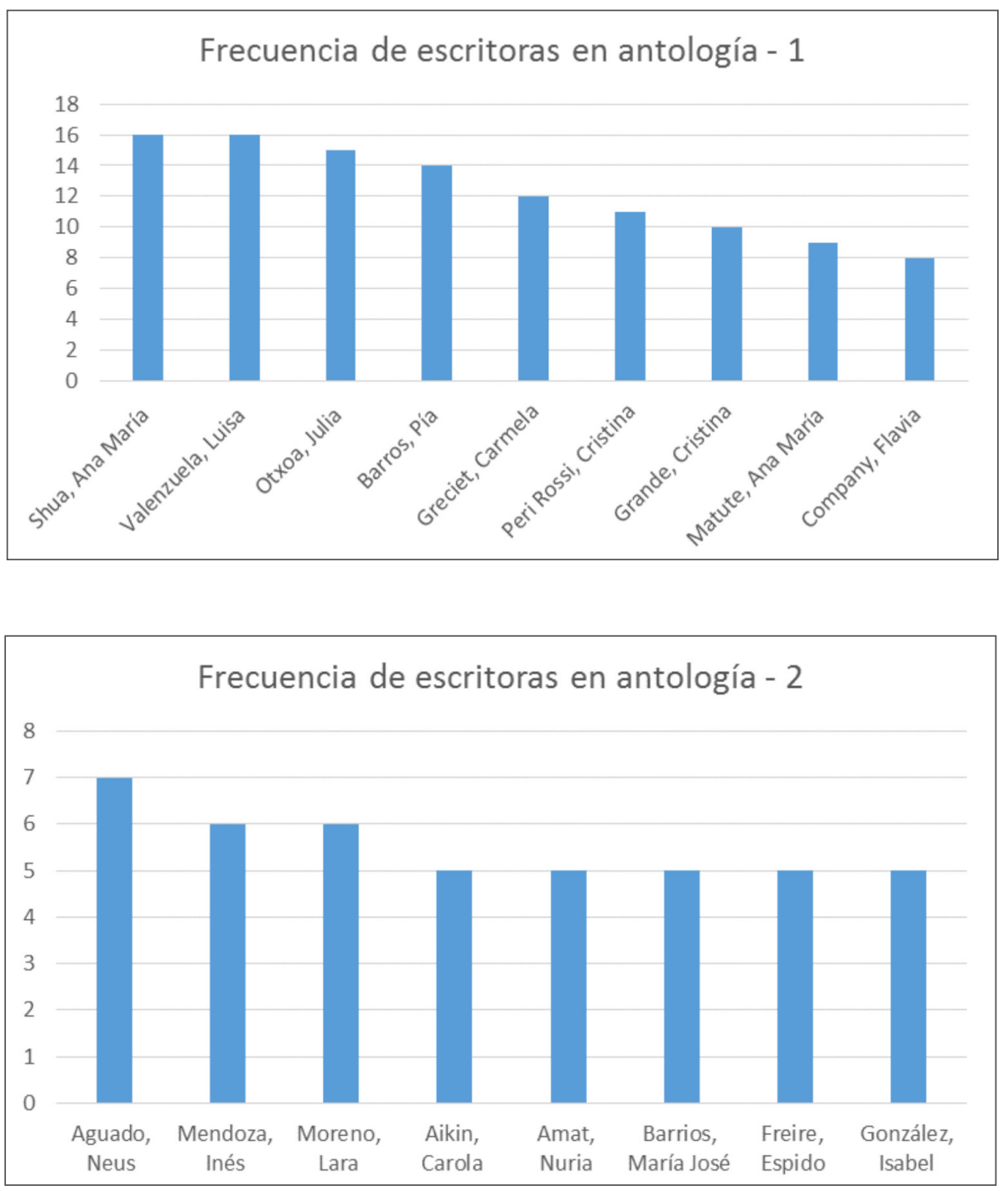

Gráfico 2 (Elaboración propia)

Si partimos de la base de que las antologías tienen una función canonizadora y, en el caso del microrrelato, suponen un instrumento de legitimación artística y literaria, es consecuente que se incorporen figuras más consolidadas en el campo literario, en detrimento de las voces más jóvenes.

Los porcentajes de frecuencia todavía palidecen más si los presentamos agregando a los escritores masculinos: 


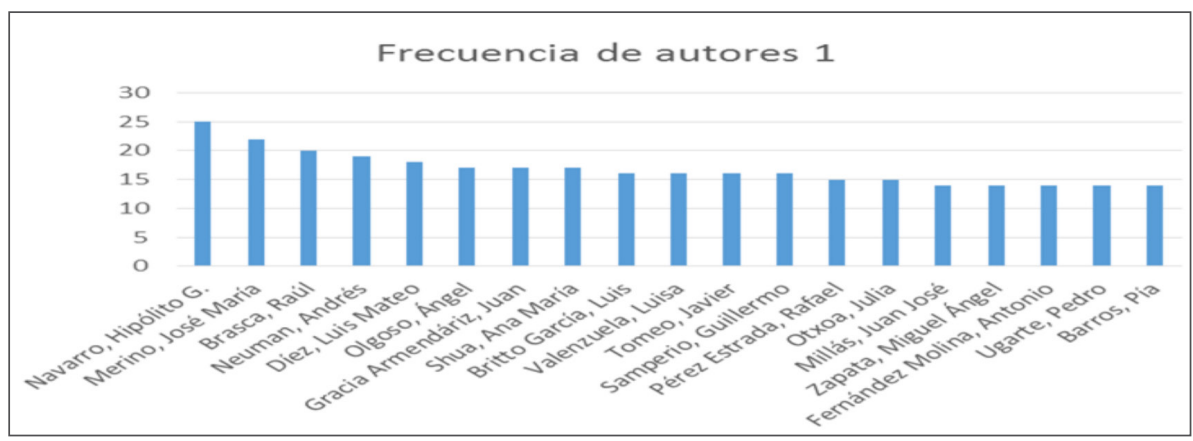

Gráfico 3 (Elaboración propia)

De los veinte con mayor número de microrrelatos seleccionados, únicamente cuatro son mujeres. De modo que, si el universo de autoras alcanzaba casi un tercio del total, su representatividad, teniendo en cuenta la autoría de los textos antologados, se sitúa todavía en franjas sensiblemente más inferiores.

Si se desagrega por antologías, el resultado ofrece guarismos similares:

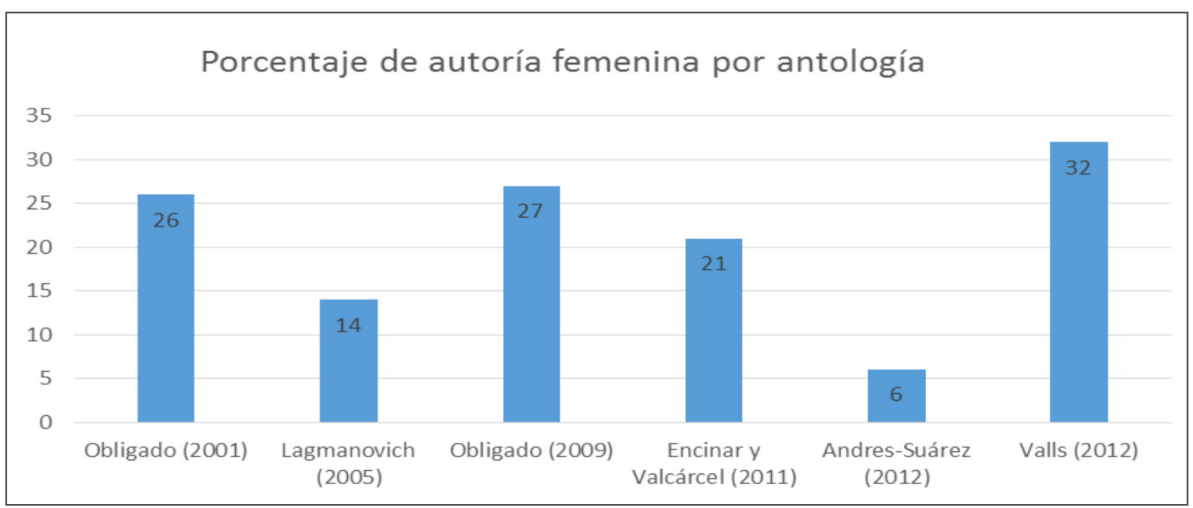

Gráfico 4 (Elaboración propia)

Las antologías de Obligado (2001 y 2009) y Encinar y Valcárcel (2011) se aproximan a la representatividad que las escritoras consiguen en otras esferas del campo literario actual, a la que solo alcanza la de Valls (2012). Esta diferencia es lógica, ya que la organización de esta última publicación persigue una muestra de las nuevas voces del microrrelato español, en las que la mujer tiene, como se ha dicho, una mayor visibilidad en el campo literario. 
No lo favorece, por motivos contrapuestos, el criterio historiográfico y la pretensión canonizadora de las antologías de Lagmanovich (2005) y Andres-Suárez (2012). En el primer caso apenas aparecen siete escritoras, de un total de cincuenta y cuatro. El mismo número se repite en la segunda publicación, pero sobre un total de setenta y dos escritores y escritoras seleccionados.

El amplio espectro temporal de ambas publicaciones, de casi un siglo (1906-2011) en el caso de Andres-Suárez (2012) y de más de uno en el de Lagmanovich (el microrrelato incluido de Rubén Darío se remonta a Azul...) explican en gran medida la ausencia de mujeres, al incorporar períodos en la que la presencia femenina era sensiblemente menor a la actual, pero también porque las listas y corpus se siguen legitimando a través de la posición que los autores ocupan en el campo y, por lo tanto, existe todavía un reconocimiento mayor hacia ellos. Conviene, no obstante, advertir que, de hecho, ambas antologías presentan un mayor número de escritoras a medida que se aproximan a épocas recientes.

\section{REPERTORIO FANTÁSTICO EN LOS MICRORRELATOS DE ESCRITORAS}

Efectuado el análisis de la presencia de autoras en las antologías, nos centramos en los contenidos de los microrrelatos, en su repertorio, en el que la narración fantástica alcanza un notable protagonismo.

En el artículo de Núñez Sabarís y Ribeiro (2020), focalizado únicamente en la antología de Valls (2012), señalábamos la abundancia de microrrelatos que incorporan el elemento fantástico o insólito. Diferenciamos ambas categorías, ya que si el primero sería un episodio que refleja el conflicto entre lo imposible y nuestra idea de lo real (Roas, 2017), el segundo aborda sucesos teóricamente posibles, pero altamente improbables, creando un efecto semejante, ya que, en definitiva, está en juego la inexplicabilidad de los hechos:

su objetivo primordial [el del relato fantástico] ha sido y es reflexionar sobre la realidad y sus límites, sobre nuestro conocimiento de esta y sobre la validez de las herramientas que hemos desarrollado para comprenderla y representarla. Ello determina que el mundo construido en los relatos fantásticos es siempre un reflejo de la (idea de) realidad en la que habita el lector. La irrupción de lo imposible en ese marco familiar supone una transgresión del paradigma de lo real vigente en el mundo extratextual y, derivado de ello, un inevitable efecto de inquietud ante la incapacidad de concebir la coexistencia de lo posible y lo imposible (Roas, 2017: 10). 
En Núñez Sabarís y Ribeiro (2020) registramos también los temas más frecuentes, que reflejan las preocupaciones generacionales de los escritores antologados — recordemos todos ellos nacidos después de 1960-. Es, por esta razón, que orientaré ahora el análisis repertorial de los microrrelatos siguiendo un criterio diacrónico, en función del año de nacimiento de las escritoras. Esta secuenciación cronológica se justifica, además, por la variabilidad temporal de lo fantástico (su categorización, su práctica), ya que su concepción no ha sido impermeable al paso del tiempo, modificándose en estrecho vínculo con los factores sociales, políticos y culturales que condicionan nuestra percepción de lo real y sus cambiantes posibilidades (cognitivas, científicas o trascendentales): «Esta definición de lo fantástico no implica una concepción estática de dicha categoría, pues esta evoluciona al ritmo en que se modifica la relación entre el ser humano y la realidad» (Roas, 2017: 10).

La primera etapa se centra, consecuentemente, en las escritoras nacidas antes de 1940 - y alguna de ellas antes del inicio del siglo- Como se ha señalado, es un grupo reducido, dadas las variables señaladas anteriormente. La mayoría aparecen con relatos únicos en las antologías de Obligado (2001 y 2009), en los que el elemento fantástico es todavía heterogéneo y poco consistente. Se mezcla la imaginación, la historia con un sentido mágico, pero no encontramos los procedimientos más reconocibles de la categoría fantástica. El microrrelato «La amiga de mamá», de Ana María Pérez Cañamares (Obligado, 2001: [15]), ${ }^{4}$ presenta una situación extraña, tal vez insólita, desde la perspectiva de un niño para insinuar la relación sentimental, con final triste, de su mamá con «la amiga de mamá». La perspectiva femenina también está en «La mujer de Galvao», de Gloria Pampillo (Obligado, 2001: [9]), que se centra en un episodio histórico y bélico, en la que la narración reivindica la heroicidad de Joana, la esposa de Manuel Galvao, ama de casa opacada por las gestas guerreras del soldado.

En «Ayyyy», de Angélica Gorodischer (Obligado, 2001: [80]), el relato fantástico aparece con mayor claridad, en una historia en la que la supuesta aparición de ultratumba del marido de la protagonista es una llamada a que la acompañe en el viaje definitivo hacia la muerte.

Dentro de este apartado, las autoras que con más frecuencia aparecen son Luisa Valenzuela y Ana María Matute. En el caso de la escritora barcelonesa, los microrrelatos se centran en un tema recurrente en la minificción: la infancia. Todos ellos proceden de su libro Los niños tontos, en los que se pro-

4 La primera antología de Obligado (2001) carece de paginación, por lo que incluimos entre corchetes la numeración que he efectuado para facilitar la localización de los textos en el libro. 
fundiza en esa etapa de la vida marcada por el descubrimiento, la crueldad, la incertidumbre o la pérdida de la inocencia, ámbitos todos ellos abiertos a lo sensorial, imaginativo e insólito. Los textos seleccionados se incluyen en la antología de Lagmanovich (2005) y Andres-Suárez (2012), que repite alguno de los relatos incluidos en la anterior selección. En ellos, el elemento fantástico no aparece de forma muy explícita - la inexplicabilidad-, ya que se juega con la ambigüedad del niño o los efectos alegóricos de la infancia. En ellos, se explora, sobre todo, la violencia social, ejercida sobre los más vulnerables, como «El hijo de la lavandera» (Lagmanovich, 2005: 101) o la crueldad infantil, como antesala de la monstruosidad adulta, como en «El niño que no sabía jugar», en la que la madre descubre los atroces pasatiempos de su hijo: «Cuando el niño llegó al borde del estanque, se agachó, buscó grillitos, gusanos, crías de rana y lombrices. Iba metiéndolos en una caja. Luego, se sentó en el suelo, y uno a uno los sacaba. Con sus uñitas sucias, casi negras, hacía un leve ruidito, ¡crac!, y les segaba la cabeza» (Lagmanovich, 2005: 103). En algunos relatos, con todo, se presentan elementos que transgreden la noción de realidad, pero, en algunos casos parece funcionar lo maravilloso, a través de la creencia religiosa («El niño que no llegó»; Lagmanovich, 2005: 99) y, en otros, el sentido alegórico del texto («El otro niño»; Lagmanovich, 2005: 102).

Luisa Valenzuela es quizás la escritora más transversal de este grupo, ya que sus microrrelatos aparecen en las antologías de Obligado (2001 y 2009), Lagmanovich (2005) y Encinar y Valcárcel (2011). A pesar de que generacionalmente se sitúa en este grupo, la mayoría de sus libros de cuentos son de los años noventa y los de microrrelatos del presente siglo, de modo que presentan notables paralelismos con las temáticas abordadas por las antologadas más jóvenes. Predominan los microrrelatos irónicos, de relaciones amorosas o sexuales insólitas y la denuncia política o social. En este último ámbito se sitúa una narrativa hiperbreve en el que la ironía mitiga el formalismo fantástico de la historia:

ESTE TIPO ES UNA MINA

No sabemos si fue a causa de su corazón de oro, de su salud de hierro, de su temple de acero o de sus cabellos de plata. El hecho es que finalmente lo expropió el gobierno y lo está explotando. Como a todos nosotros (Lagmanovich, 2005: 257).

El siguiente grupo generacional está constituido por las autoras nacidas entre 1940 y 1959. Pertenecen ya a la sección que Lagmanovich (2005) denominó «El microrrelato hoy». En efecto, son las escritoras que en la actua- 
lidad asociamos a las clásicas de la minificción, de ahí su mayor frecuencia en las diferentes antologías, tal como se ha señalado. Pía Barros, Ana María Shua, Neus Aguado, Julia Otxoa o Cristina Peri Rossi son nombres indispensables en el cuento y microrrelato hispano.

Los textos seleccionados responden a las características más destacadas de la narrativa hiperbreve, sin embargo, lo fantástico no está todavía muy presente en el conjunto de los microrrelatos incorporados. Abundan las historias que se explican por las referencias intertextuales como «Hans y Gretel» (Lagmanovich, 2005: 191) o «De como el Quijote fue quemado en Morano» (Andres-Suárez, 2012: 247), ambos de Julia Otxoa, o el de Neus Aguado, «Lo tiene muy complicado señora Tolstoi» (Encinar y Valcárcel, 2011: 206).

Es notable también el posicionamiento feminista en varios de los relatos, apuntando a situaciones de humillación o explotación de la mujer. En «Palomeras de San Roque» (Lagmanovich, 2005: 189), Julia Otxoa metaforiza las cazas de las palomas para evidenciar las agresiones sexuales y la violencia machista, aludiendo también a la imagen icónica de Drácula: «el rito continúa y esos cazadores, con los labios aún chorreando sangre, besan en la boca a las mozas que quieren buscar novio. Ya que dice la leyenda que los besos mojados en sangre de paloma son los mejores aliados del amor» (Lagmanovich, 2005: 189). A su vez, Pía Barros y Ana María Shua ponen de manifiesto la explotación sexual de las prostitutas, su cosificación y deshumanización. «Sin claudicar» (Lagmanovich, 2005: 232), de Barros, está dedicada a «la más barata del puerto», que en sus cincuenta años conserva la guirnalda de la última navidad en que fue niña. Las historias de burdeles también protagonizan «Una mujer», de Ana María Shua, que sigue el tono predominante de la obra de la autora, por ejemplo en Casa de geishas:

\section{UNA MUJER}

En la puerta del burdel, un hombre pregona la mercadería a los viandantes. Les ofrece una mujer muy blanca pero cubierta de lunares y otra dada a pulposas fantasías y otra de ojos como espadas y otra capaz de tocar tres instrumentos al unísono y otra que ruge como el rotor de un helicóptero desbocado y otra extranjera y otra que se olvida de su propio nombre en cada recodo de su sexo. Sin embargo, adentro hay solamente una mujer. Sin embargo, el hombre no miente (Lagmanovich, 2005: 191),

Aunque Shua echa mano de un recurso que podríamos asociar a lo fantástico, el sentido del texto hace prevalecer la orientación metafórica de la 
historia. Por su parte, Cristina Peri Rossi, en «Cuando los alfileres se rebelaron» (Lagmanovich, 2005: 244), hace animar las piezas del ajedrez —en un recurso ya decididamente fantástico — para relatar la violación y el asalto asesino de los rebeldes alfiles a la reina.

El microrrelato que, no obstante, presenta recursos más convencionalmente fantásticos es «Rehilete», de Neus Aguado:

\section{REHILETE}

La poseída por el diablo miraba a las víctimas con deseo. Después disparaba su ojo mecánico y desaparecía. Acostumbraba a utilizar el viejo método de la mirada que todo lo puede. Una vez había elegido con digna lentitud el cuerpo que más favores pudiera dispensarle se ponía en guardia. Acechaba las puertas de alcobas, lavabos y ascensores. Miraba a través del cristal de la cabina hasta que sus ojos se convertían en puñales y el daño que ocasionaban era irresistible. Daba las buenas noches mirando fijamente el torso y el sexo. Entraba bruscamente en el cuarto de baño y captando la desnudez, en su absoluta limpieza, la recorría avarienta: primero con los ojos, después con las manos, más tarde con los labios, y finalmente sus dientes marcaban el paso del deseo por las venas. $\mathrm{Y}$ la víctima caía, sorprendida, en un charco de sangre.

Los ojos de la poseída se hacían cada día más hermosos (Encinar y Valcárcel, 2011: 202).

Aguado recurre aquí a los trazos clásicos de las narraciones fantásticas y de terror: la femme fatale con poderes, de belleza arrebatadora y poseída por el diablo, que acecha de manera implacable a sus víctimas. Velázquez Velázquez (2019: 607) señala, a este propósito, un cambio en la visión del personaje femenino, una vez que «entre la mujer devorada, víctima, y sumisa, por un lado; y la mujer devoradora, monstruosa, y agentiva, por otro, existe claramente entre las escritoras mujeres una preferencia por la segunda».

Concluimos el repertorio con las voces más contemporáneas del microrrelato. Como se ha señalado, constituyen el grupo más numeroso de las autoras antologadas, aunque pocas aparecen en más de una antología. Es una generación habituada a la escritura de la minificción y a la publicación monográfica de relatos hiperbreves. Algunos de los textos seleccionados vieron la luz inicialmente en la red, poniendo de relieve el tránsito fluido de la blogosfera al libro en la minificción (Pujante Cascales, 2018 y Hernández, 2018).

En este grupo abundan los temas que se centran en las crisis existenciales, de pareja, problemas de la infancia, representaciones de la identidad o del cuerpo, en sus diferentes metamorfosis (animalización, cosificación, desmem- 
bración o multiplicación) (Núñez Sabarís y Ribeiro, 2020). En todos ellos cobra, además, un papel de mayor protagonismo el personaje femenino que amplía, en general, sus modos y espacios de representación, sobre todo en el microrrelato escrito por mujeres (Velázquez Velázquez, 2019: 599).

En ellos los recursos a lo fantástico o insólito son frecuentes. En algunos el elemento fantástico se construye alrededor de juegos lingüísticos, como el relato «Sirena», de Carmela Greciet (Andres-Suárez, 2011: 318), cuya historia es absolutamente realista - una chica que se arroja desde un acantilado en silla de ruedas - pero el título modifica el sentido e induce a una interpretación sobrenatural de la narración, en virtud de las dudas sobre la identidad de la protagonista. Más obvio es el microrrelato de la misma autora «Cierta luz» (Obligado, 2009: 48), en el que Marga, la pareja del protagonista, se termina subsumiendo por la tubería de la bañera en la que habían hecho el amor por última vez, como esperanza de reconciliación. Esta problematización de la vida en pareja, del cuerpo femenino, de su cosificación —o en este caso evaporación- será un tema frecuente, tal como en sus predecesoras. "Hotel Ibis», de Cristina Grande (Encinar y Valcárcel, 2011: 273); «Mujer devorando a una pantera» y «Reconciliación», de María José Barrios (Valls, 2012: 302 y 303), o «Ristel», de Susana Camps (Valls, 2012:113), entre otros muchos microrrelatos, se sitúan en esta misma temática.

En varios de ellos se expresa, en clave fantástica, la metamorfosis humana, como en «El beso», de Susana Barragués Sainz, al simbolizar los cambios de niña a adulta:

El Beso

La niña que se abandonaba por primera vez a un beso larguísimo, y desplegaba de súbito unas grandes alas, gruesas y húmedas, que le nacían bajo las costillas.

Y mientras besaba, mitad hembra mitad ganso, esponjaba las plumas gustosamente hacia la brisa (Obligado, 2009: 185).

En otras ocasiones se denuncia, una vez más, la brutalidad de la decadencia de las relaciones amorosas y la depredación masculina sobre la mujer. El siguiente texto de Carolina Akin es una buena muestra de ello:

\section{S.O.S. MUTACIÓN POBLACIONAL}

Hoy desperté con la extraña sensación de haber dejado de ser quien era y casi me sentí feliz. Pero comenzaron los timbrazos, del móvil y de la puerta, incapaz 
de soportarlo me levanté a abrir. Bofetada de perfume: ella. ¿Quién si no? Esos ojos aguados, el furioso cacareo. Bendije mi suerte, la agarré por el pescuezo y se lo medio retorcí. Luego me entretuve en irle arrancando plumas: me la como, no me la como.

De nuevo el móvil, hipa que hipa, y el mismo mensaje: SOS Mutación poblacional. Al instante estalla el lío: gruñidos, bramidos, cacareos histéricos por todo el edificio, el olor de la sangre entrando por las ventanas del patio, reptando bajo las puertas del A. del B. Ahí empecé a inquietarme, a dudar de mi suerte, de mi nueva condición. Agarré a mi pobre víctima despeluchada y le rugí: «Dime quién soy, en qué me he convertido». Ella meneó rabiosa el pico, diablo de gallina, y de un bocado me la zampé (Obligado, 2009: 66).

Nuria Mendoza e Isabel González, a su vez, reflejan, con ironía y sarcasmo, la incomprensión, el tedio y el distanciamiento en las relaciones de pareja, acudiendo, de nuevo, a lo fantástico. ${ }^{5}$ En el relato de Nuria Mendoza «Pura lascivia», además, con un recurso muy frecuente en la narrativa hiperbreve, que consiste en la animación de los objetos personales o las prendas de ropa, como los mundos paralelos (afectivos y sexuales) que no viven sus propietarios. Otro microrrelato que se puede asociar a este es «Jerseys y cazadoras», de Beatriz Alonso Aranzábal (Valls, 2012: 106).

\section{PURA LASCIVIA}

Voy a ser directa: tu esponja y la mía tienen un lío. Lo he descubierto esta mañana, en el baño.

Tu esponja — tan estilizada, pero de curvas marcadas - estaba poniendo a cien a la mía, que de repente me parecía un poco masculina, más tosca en su superficie, como si necesitara un afeitado.

Cuando me duchaba, las vi frotarse sin disimulo. Aprovechaban el agua caliente para abrir sus poros como bocas y exfoliarse en posturas admirables. Mi esponja cabalgaba a la otra, que se expandía, se acoplaba, se retorcía empapada y pedía a gritos un poco de gel. Hasta parecían oírse gemidos, no exagero.

Eso por no hablar de los botes de champú: el mío, cuadrado y ancho de espaldas, se estaba insinuando descaradamente al tuyo, pequeñito y coqueto.

Y mejor no sigo, porque a la hora de secarme me pareció que entre mi albornoz y tu toalla se fraguaba algo.

En mi baño están en pie de guerra y tú tan lejos. Ay, me dan una envidia (Valls, 2012: 204).

5 Es un reflejo del lugar líquido que ha adquirido la relación de pareja en la posmodernidad, de la que se hace frecuentemente eco el microrrelato (Velázquez Velázquez, 2019: 608). 
Isabel González, por su parte, echa mano del universo léxico de las frutas, como sustituto de la insatisfacción sexual de la protagonista. Adopta también la desmembración corporal para llevar a cabo las estrategias fantásticas del microrrelato:

\section{ANORGASMO A MANO}

Mientras cabalgo sobre mi esposo, escarbo en las filigranas del cabecero y busco tras los pliegues de las cortinas: "Oh sí, mi amor sí», hurgo en los cajones, indago en el joyero, miro bajo las alfombras. «Oh, sí, mi amor sí», sigo buscando, me estiro, alcanzo la puerta, me rompo, me desintegro, mi mano sale disparada del dormitorio, corre a gatas por el pasillo, entra en la cocina, abre la nevera y entonces sí, "oh sí, mi amor sí», acaricia quién sabe qué, lichis de Madagascar, frutas exóticas, mermelada de maracuyá. «iAh!» (Valls, 2012: 227).

Por último, Patricia Esteban Erlés, juega intertextualmente con el microrrelato «Cuento de horror», de Juan José Arreola, para crear su propio fantasma, que ahora pone de relieve los procesos de emancipación sentimental femenina, con una evidente carga irónica y sarcástica:

\section{FANTASMA}

El hombre que amé se ha convertido en fantasma. Me gusta ponerle mucho suavizante, plancharlo al vapor y usarlo como sábana bajera las noches que tengo una cita prometedora (Obligado, 2009: 201).

\section{Conclusión}

Con el microrrelato de Esteban Erlés ponemos punto y final a este trabajo en el que se ha abordado la presencia de las escritoras en las antologías de microrrelato, así como la recurrencia a lo fantástico en el repertorio de la minificción. En una dimensión más cuantitativa de nuestro análisis, la frecuencia de la inclusión de autoras en las antologías analizadas presenta las mismas características de progresiva visibilidad verificada en otras esferas del campo literario. Si se verifica una gradual presencia de las escritoras más jóvenes, lo cierto es que la representatividad canónica todavía sigue evidenciando modelos conservadores, en lo que respecta a género y edad.

En lo que se refiere a los microrrelatos de las escritoras se significan por su sensibilidad hacia cuestiones políticas, sociales o humanas, de las que no se 
puede deslindar la preocupación por las cuestiones de género - ya en forma cómica, irónica o trágica-, como uno de los grandes desafíos del siglo XXI. El recurso a lo fantástico —o insólito- aparece, en los textos seleccionados, cada vez como una estrategia más consciente para potenciar las capacidades comunicativas y literarias de la minificción.

\section{BiBLIOGRAFÍA}

ANDRES-SuÁrez, Irene (2012): Antología del microrrelato español (1906-2011). El cuarto género narrativo, Cátedra, Madrid.

- (2013): «Corpus del microrrelato español», El Cuento en Red. Revista electrónica de la teoría de la ficción breve, 27, pp. 3-10.

Asociación Colegial de Escritores de España (2019): Libro Blanco del Escritor (Sobre la situación profesional de los escritores en España), Asociación Colegial de los Escritores de España, Madrid.

Asociación de Escritoras e Escritores en Lingua Galega (2020): Preparación do libro branco da Asociación de Escritoras e Escritores en Lingua Galega. Informe de resultados, s.l., s.n.

EnCINAR, Ángeles, y Carmen Valcárcel (eds.) (2011): Más por menos. Antología de microrrelatos hispánicos actuales, Sial, Madrid.

HeRnÁNDEZ, Darío (2016): Un centímetro de seda: antología del microrrelato español, Menoscuarto, Palencia.

- (2018): «Enredaderas de la minificción. Algunos de los microrrelatistas en España con mayor presencia en Internet», en Ana Calvo Revilla (ed.), Elogio de lo mínimo. Estudios sobre el microrrelato y minificción en el siglo XXI, Iberoamericana/ Vervuert, Madrid/Frankfurt am Main, pp. 113-124.

Hernández, Darío, y Fernando Valls (2014): «Para una bibliografía casi completa de los estudios sobre el microrelato español», El Cuento en Red. Revista electrónica de teoría de la ficción breve, 29, pp. 3-19.

Lagmanovich, David (ed.) (2005): La otra mirada. Antología del microrrelato hispánico, Menoscuarto, Palencia.

NúÑEz SABARís, Xaquín (2013): «Resistencia y canonización en el microrrelato: de la teoría y crítica a las antologías especializadas», Pasavento. Revista de Estudios Hispánicos, 1.2, pp. 143-164. <https: / / doi.org/10.37536/ preh.2013.1.2.644>.

— (2017): «Microrrelato y antología» [base de datos]. Disponible en http: / / cehum.ilch. uminho.pt/microrrelatos_xaquinnunez [15-6-2021].

- (2017): «Microrrelato y campo literario: un análisis relacional y de corpus de las antologías contemporáneas (2000-2017)», Microtextualidades. Revista Internacional de microrrelato y minificción, 1, pp. 78-104.

NúÑEZ SABARís, Xaquín, y Eunice RIBEIRO (2020): «Taxonomía del microrrelato hispánico del siglo xxI: propuestas metodológicas de investigación en (la) red», en Ana 
Calvo Revilla y Eva Ramos Álvarez (eds.), Microrrelato hipermedial: aproximaciones teóricas y didácticas, Peter Lang, Berlín, pp. 79-98.

Obligado, Clara (ed.) (2001): Por favor, sea breve. Antología de microrrelatos, Páginas de Espuma, Madrid.

- (ed.) (2009): Por favor, sea breve 2. Antología de microrrelatos, Páginas de Espuma, Madrid.

Pujante Cascales, Basilio (2018): «Del byte a la página. Transiciones entre la web y el libro en el microrrelato español», en Ana Calvo Revilla (ed.), Elogio de lo mínimo. Estudios sobre el microrrelato y minificción en el siglo XXI, Iberoamericana/ Vervuert, Madrid/Frankfurt am Main, pp. 93-111.

RoAs, David (dir.) (2017): Historia de lo fantástico en la cultura española (1900-2015), Madrid-Frankfurt am Main, Iberoamericana-Vervuert.

RoAs, David, y Ana CASAS (2016): Voces de lo fantástico en la narrativa española contemporánea, e.d.a., Málaga.

Valls, Fernando (ed.) (2012): Mar de pirañas. Nuevas voces del microrrelato español, Menoscuarto, Palencia.

Velázquez VelázQuez, Raquel (2019): «Quaerens quem devoret: El resurgimiento de la mujer mantis o mujer devoradora en el microrrelato fantástico español del siglo xxI», Bulletin of Hispanic Studies, 96.6, pp. 595-610. <https://doi. org/10.3828/bhs.2019.35>. 